\title{
Influence of the Woven Structure on the Initial Fracture Behavior of Roving Glass Fabric Reinforced Composites
}

\author{
Zhilan Xu, Atsushi Yokoyama \\ Advanced Fibro-Science, Kyoto Institute of Technology, Kyoto, Japan \\ Email: lanlan-xu@hotmail.com
}

How to cite this paper: $\mathrm{Xu}, \mathrm{Z}$. and Yokoyama, A. (2018) Influence of the Woven Structure on the Initial Fracture Behavior of Roving Glass Fabric Reinforced Composites. Open Journal of Composite Materials, 8, 54-67.

https://doi.org/10.4236/ojcm.2018.82005

Received: December 19, 2017

Accepted: April 22, 2018

Published: April 25, 2018

Copyright ( 92018 by authors and Scientific Research Publishing Inc. This work is licensed under the Creative Commons Attribution International License (CC BY 4.0).

http://creativecommons.org/licenses/by/4.0/

\begin{abstract}
In this paper, investigation on the initial fracture behavior was carried out on roving glass woven fabric reinforced composites which were manufactured by hand lay-up method. Two kinds of roving glass woven fabrics of different FAW (Fabric Area Weight) and crimp ratio, Type A of $570 \mathrm{~g} / \mathrm{m}^{2}$ and Type B of $800 \mathrm{~g} / \mathrm{m}^{2}$, were adopted as reinforcement in this study. Tensile test was conducted and tensile properties were discussed on specimens of 6 degrees $0^{\circ} / 5^{\circ} / 10^{\circ} / 80^{\circ} / 85^{\circ} / 90^{\circ}$. The initial fracture behavior was observed on 0 degree and 90 degree and the fracture mechanism was compared and discussed among $5^{\circ} / 10^{\circ} / 80^{\circ} / 85^{\circ}$. The results showed that Type B has higher tensile modulus and tensile strength than that of Type A. And different initial fracture behaviors between two kinds of materials was observed and analyzed, which indicated that the crimp ratio plays an important role of woven fabric reinforced composites in fracture mechanism.
\end{abstract}

\section{Keywords}

Glass Roving Cloth, Woven Structure, Crimp Ratio, Initial Fracture Behavior

\section{Introduction}

Recent decades, textile fabrics used as reinforcements for manufacturing composites are spreading in various fields, such as aerospace, automotive, construction and basic facilities industries [1] [2] [3] [4]. Woven fabrics, characterized with the special structure form, are widely used as reinforcement of textile composites in structural applications by far [5] [6]. Generally woven fabrics consist of two sets of yarn components, known as warp yarns and weft yarns [7]. The overlap structure in the cross section provides with relatively good dimensional 
stability [8].

Roving cloth, as one of the woven fabrics, is characterized with the cross section of the warp fiber bundles and weft fiber bundles, which are usually used as reinforcement for laminate molding [9] [10]. Roving cloth has the advantage that it can be used for relatively complex shapes or curvatures. However, due to the crimp of the warp and weft fiber bundles, there will be a tendency for the load direction fiber bundles to stretch [12] [13], forming a compressive stress against the transverse fiber bundles within the cross-section area [11] [12] [13] [14]. Generally, final fracture of composites is considered to be caused by the accumulation of these microcracks or fractures [15] [16]. Thus, initial fracture, which represents the initiation of micro fracture, is considered to be significant in determining the fracture mechanism. GFRP (glass fiber reinforced plastic) materials, characterized by high strength, low cost, low density, corrosion resistance, are also adopted in the form of glass woven fabric as reinforcements. Two kinds of glass roving clothes were used in this study, and effort was made to find out the fracture mechanism, especially the initial fracture behavior.

In previous works, many researchers focused on the mechanical properties as well as the fracture mechanism of glass woven cloth reinforced composites. Demircan, O. carried out the investigation of the fracture process and mechanisms of glass roving and glass cloth composites [7]. García, I. et al. tested the cross-ply glass-reinforced polyester composites in a direction parallel to one of the directions of reinforcement. The results showed that the crack spacing measurements are against applied stress for specimens with differing ply thicknesses [17]. Boccardi, S. et al. conducted a research that focused on the behavior of inter-laminar graded interface strength (IGIS) under impact. Results highlight the role played by the stacking sequence in the IGIS laminate [18]. Jaafer and Muslem [19] conducted tests on DCB woven roving and CSM interface layers and observed fibre bridging but did not calculate the associated strain energy release rates. Ono, K., Fujii, Y., and Wada, A. investigated the possibility of non-destructive examination with ultrasonic wave testing for mechanical damage of glass fiber reinforced plastics [20].

Because of the complicated microstructure of woven fabric, it is of significance to understand of mechanical mechanism of textile fabric reinforced composite materials. There are references [21] [22] showing that initial fracture occurred in woven fabric reinforced composites has been observed in transverse fiber bundles, which has a significant effect on the mechanical properties of composites. Zako, M., and Uetsuji, Y. [23] investigated the damage behavior of woven fabric reinforced FRP, and simulated by finite element analysis using an anisotropic damage model based on damage mechanics. $\mathrm{Xu}, \mathrm{Z}$. et al. chose $\mathrm{CF} / \mathrm{GF}$ hybrid woven fabric as the reinforcement and the initial fracture properties was discussed [24] [25].

In this paper, investigation on the initial fracture behavior was carried out on roving glass woven fabric reinforced composites manufactured by the hand lay-up method. Two kinds of roving glass woven fabrics of different FAW (Fa- 
bric Area Weight) were adopted in this study. Tensile tests combined with $\mathrm{AE}$ (acoustic emission) measurements [26] [27] were conducted and the initial fracture behavior was observed. These two kinds of composites molded by fabrics with different crimp ratio showed difference in tensile properties as well as different fracture mechanism. The results indicated that the crimp ratio decided by the yarn density and fiber bundle tex, is playing an important role in the fracture mechanism. In the off-axis cases of $5^{\circ} / 10^{\circ} / 80^{\circ} / 85^{\circ}$, the fracture mechanism and the shear stress were compared and discussed [28].

\section{Materials and Experimental Methods}

\subsection{Materials and Specimens}

In this paper, two kinds of roving glass woven fabrics of different FAW (Fabric Area Weight), $570 \mathrm{~g} / \mathrm{m}^{2}$ and $800 \mathrm{~g} / \mathrm{m}^{2}$, were adopted. Unsaturated polyester resin (150 HRBQTNA, Showa Denko K.K.) was adopted as the matrix. The glass roving clothes manufactured by Hokuriku Fiberglass Co., Ltd are in plain structure as showing in Figure 1. The one with lighter FAW is named as Type A (570 $\left.\mathrm{g} / \mathrm{m}^{2}\right)$, and the heavier one is named as Type $\mathrm{B}\left(800 \mathrm{~g} / \mathrm{m}^{2}\right)$. Detailed information of the glass fiber bundle (Nitto Boseki Co., Ltd.), such as linear density and yarn density, is listed in Table 1. It can be seen that fiber bundles of same linear density were used while the ends per inch for the warp direction and the picks per inch in the weft direction are different. And Type A is of relatively higher yarn density. In this study, the warp direction is defined as 0 degree and the weft direction as 90 degree.

The glass roving cloth reinforced composites were manufactured by hand lay-up molding method for only 1 ply for the purpose of reveal the crack

Table 1. Information of the two types of roving glass cloth.

\begin{tabular}{ccccccc}
\hline & & $\begin{array}{c}\text { Linear density } \\
(\mathrm{TEX})\end{array}$ & $\begin{array}{c}\text { Yarn density } \\
(\mathrm{N} / 25 \mathrm{~mm})\end{array}$ & $\begin{array}{c}\text { Crimp } \\
\text { percentage } \\
(\%)\end{array}$ & $\begin{array}{c}\text { Bundle area } \\
\left(\mathrm{mm}^{2}\right)\end{array}$ & $\begin{array}{c}\text { Bundle } \\
\text { distance } \\
(\mathrm{mm})\end{array}$ \\
\hline \multirow{2}{*}{ Type A } & Warp & 1150 & 6.5 & 14.4 & 1.22 & 4.90 \\
Type B & Weft & 1150 & 5.8 & 11.2 & 1.08 & 5.12 \\
\hline & Weft & 2300 & 4.6 & 13.0 & 1.77 & 6.95 \\
\hline & & & 3.8 & 10.7 & 1.50 & 7.56 \\
\hline
\end{tabular}

Figure 1. Photographs of the two types of roving glass cloth. 
propagation and fracture mechanism. After the fabrication, the composite board was cut to the size of $200 \mathrm{~mm} \times 20 \mathrm{~mm}$ (length $\times$ width) according to ASTM D3039 according to 6 orientations $0^{\circ} / 5^{\circ} / 10^{\circ} / 80^{\circ} / 85^{\circ} / 90^{\circ}$. The thickness of Type A is approximately $0.60 \mathrm{~mm}$, while Type B is approximately $0.65 \mathrm{~mm}$, a little thicker than Type A. Cross-sectional observation was carried out and the crimp percentage for both the 0 and 90 degree directions of Type A and Type B was calculated, and is showed in Table 1. Crimps are formed because of the weaving process. It can be seen from Figure 1 and Table 1 that Type A is of relatively higher yarn density, and the crimp ratio of Type $\mathrm{A}$ is slightly higher than that of Type B. It means for the same unit length, the fiber bundle length of Type A is longer than that of Type B.

\subsection{Experimental Methods}

Mechanical investigation of the tensile properties was carried out on specimens in 6 degrees $0^{\circ} / 5^{\circ} / 10^{\circ} / 80^{\circ} / 85^{\circ} / 90^{\circ}$. The tensile tests were carried out on an Instron universal testing machine at a speed of $1 \mathrm{~mm} / \mathrm{min}$ and the test room temperature was $22^{\circ} \mathrm{C}$ according to the ASTM D3039. (Specimen number $\mathrm{N}=3$ ). For $0^{\circ}$ and $90^{\circ}$, which are also defined as on-axis cases, the fracture progress during the tensile test has been observed by take video. During the tensile tests, an $\mathrm{AE}$ (acoustic emission) device was used in order to detect when the initial fracture occurred. A video was also shot in order to understand the fracture process. In the photographs collected from the video at different strain stages, three main periods can be identified to depict the fracture process. Combined with the $\mathrm{AE}$ data and the video footage, the initial fracture behavior has been discussed. For $5^{\circ} / 10^{\circ} / 80^{\circ} / 85^{\circ}$, which are defined as off-axis cases, tensile modulus, tensile strength were also tested and discussed. Besides, the difference of deferent degrees, and the comparison between Type A and B has been discussed and summarized.

\section{Experimental Results and Discussion}

\subsection{Tensile Results of On-Axis Cases}

The stress-stain curves are illustrated in Figure 2, and details of the results of the tensile tests are shown in Figure 3, and Table 2. It can be known that the tensile modulus of Type B is similar with Type A, and the tensile modulus of the 90 degree direction is higher than that of the 0 degree direction.

On the other hand, the tensile strength of Type B turned out to be much higher than that of Type A for both the 0 and 90 degree directions. The fiber bundle cross section area ratio of Type A and Type B was calculated and this value could be referred as an index similarly with $V_{f}$ (volume fraction of reinforcing fibers). The result showed the value of Type A is slightly higher than that of Type B, which is revealing that Type A might get higher tensile strength. However, it does not agree with the tensile strength result.

When it comes to the elongation, it can be known from Table 2 that the 


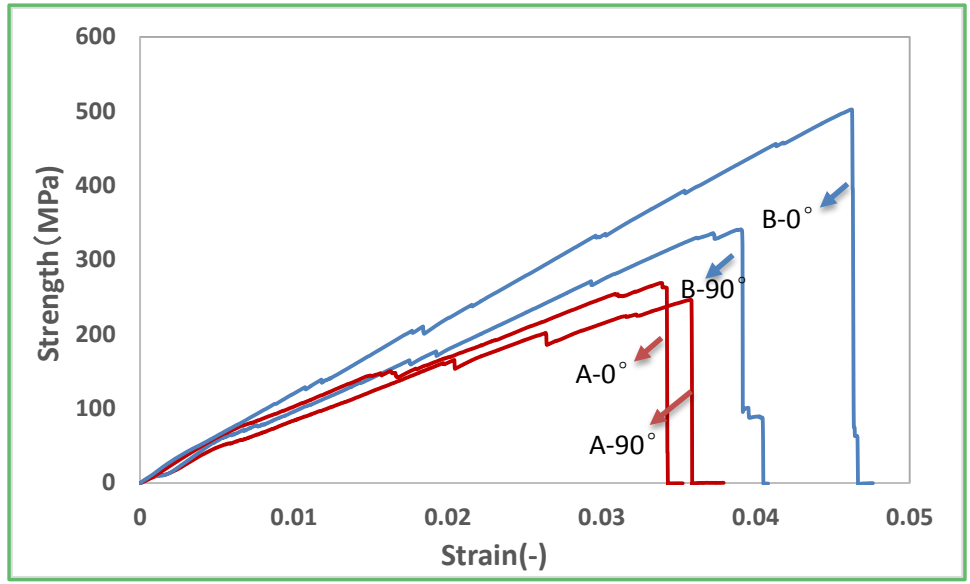

Figure 2. Stress-strain curves of two types of GFRP.

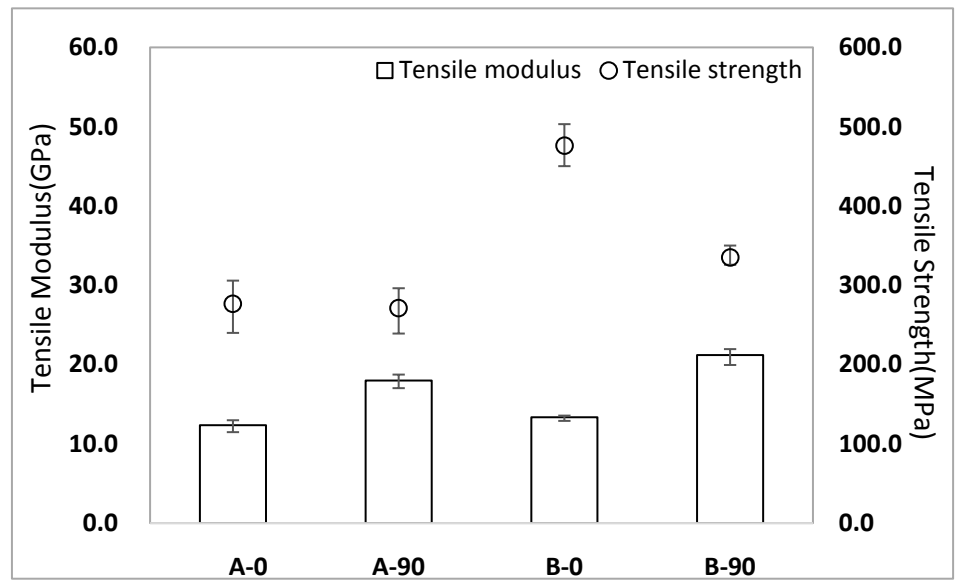

Figure 3. Tensile modulus and tensile strength of two types of GFRP.

Table 2. Tensile results of two types of GFRP.

\begin{tabular}{cccccc}
\hline Type & Degree & $\begin{array}{c}\text { Tensile modulus } \\
(\mathrm{GPa})\end{array}$ & $\begin{array}{c}\text { Tensile strength } \\
(\mathrm{MPa})\end{array}$ & $\begin{array}{c}\text { Elongation } \\
\text { rate }(\%)\end{array}$ & $\begin{array}{c}\text { Initial fracture } \\
\text { stress }(\mathrm{MPa})\end{array}$ \\
\hline \multirow{2}{*}{$\mathrm{A}$} & 0 & 12.3 & 276.7 & 3.5 & 34.7 \\
& 90 & 18.0 & 271.2 & 3.9 & 33.7 \\
& 0 & 13.3 & 476.3 & 4.5 & 35.7 \\
$\mathrm{~B}$ & 90 & 21.2 & 335.0 & 4.8 & 38.7 \\
\hline
\end{tabular}

elongation rate for Type B is higher than Type A. This would be taken as one of the reasons for the high tensile strength of Type B. But the reason why Type B achieved higher elongation should be found out firstly because the crimp ratio of Type B is lower than that of Type A which indicated Type A should have got higher elongation.

Otherwise, the initial fracture results detected by acoustic emission showing in Table 2 revealed that for both Type A and Type B in both 0 degree and 90 degree directions, the initial fracture stress values are similar. 


\subsection{Initial Fracture Process and Observation}

In order to decide where exactly the initial fracture happened, specimens were under tensile testing and stretched to 1.3 times the initial fracture stress and stopped. Then observation was carried out on the longitudinal cross section by optical microscopy. From the photographs shown in Figure 4, it can be clearly seen that transverse cracks first occurred in the transverse fiber bundles, which can be regarded as contacted to the initial fracture stress.

The fracture processes are illustrated by still images from the video in Figure 5. It can be obviously observed that transverse cracks appeared within the transverse fiber bundles at the very early stage. And with the transverse crack increased, another type of cracks in wave shape began to appear between transverse fiber bundles. The schemas of the transverse crack and the wave shape crack are illustrated in Figure 6(a) and Figure 6(b). The wave shape cracks formed because of the existence of the crimp. With the loading going higher, the fiber bundles along the load direction were stretched and had a tendency to become straight, which gave a compressive stress to the transverse fiber bundles. The resin rich area between the transverse fiber bundles was compressed and wave shape cracks formed along the iso-stress surface, which could be the direct reason leading to the final fiber bundle breaking. The wave shape cracks showing in Figure 6(b) are characteristic cracks appearing in woven fabric reinforced composited because of the woven structure.

There were several period before the final fracture can be summarized during the fracture period for both Type A and Type B involved with transverse cracks and wave shape cracks. Schemas are summarized and illustrated in Figure 7(a) for Type A and Figure 7(b) for Type B.

1) Firstly, for both Type A and Type B, transverse cracks occurred firstly in the transverse fiber bundles, and then the number of transverse cracks increases. During this period, the interface between the glass fibers and the resin is subjected to most of the load. White line of cracks can be observed in the cross section area of the warp and weft fiber bundles.

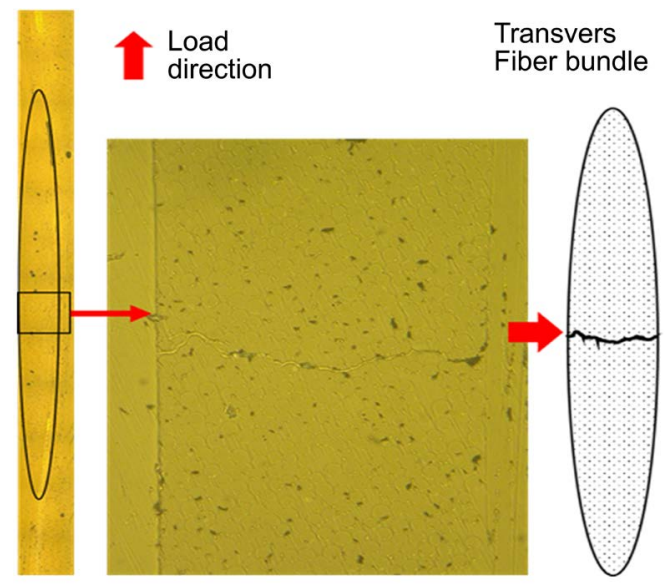

Figure 4. Cracks observed in transverse fiber bundles as initial fracture. 


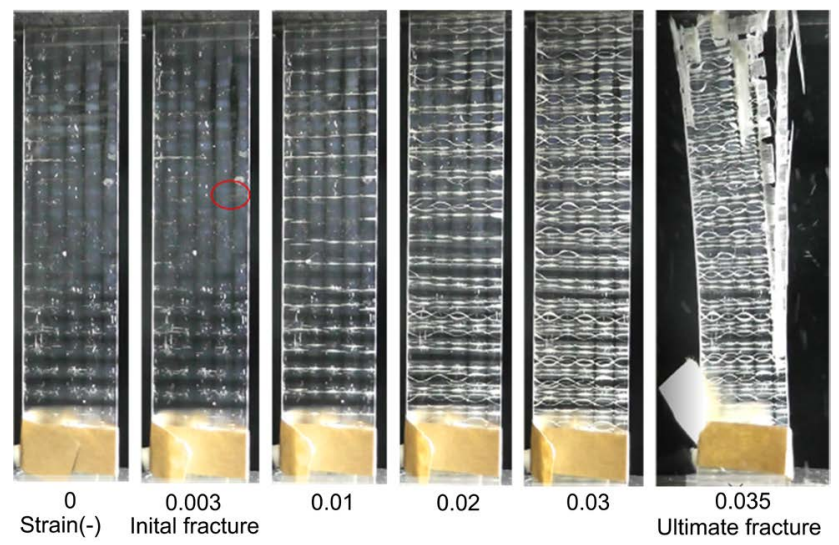

(a)
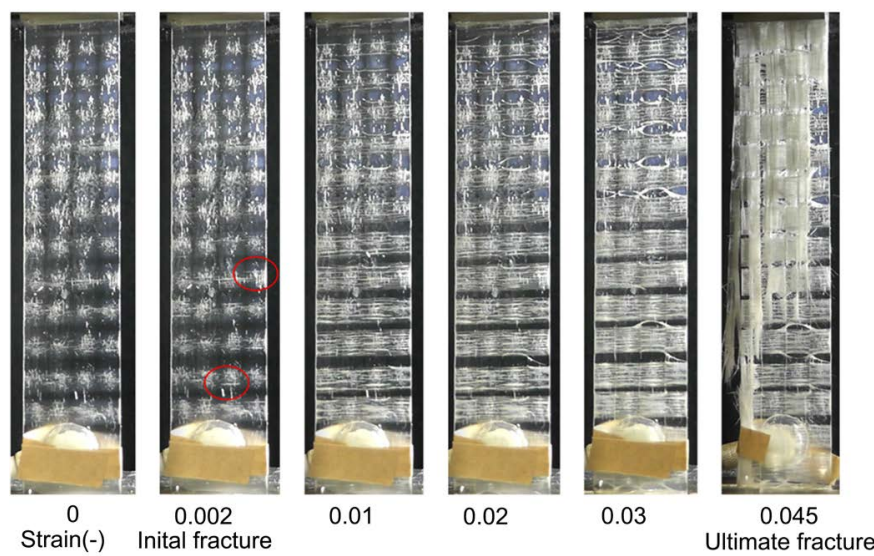

(b)

Figure 5. Fracture process during tensile test. (a) Type A; (b) Type B.
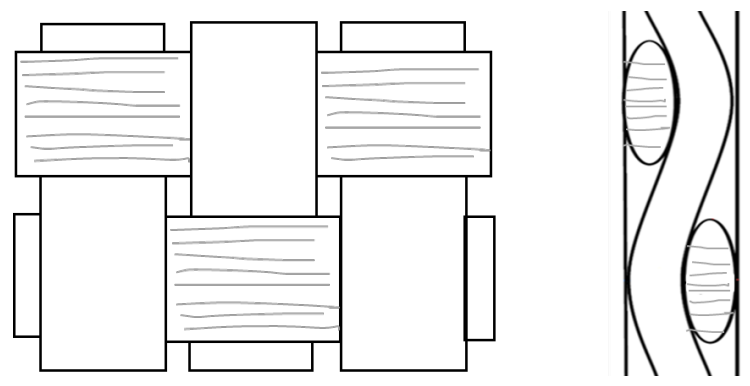

(a)
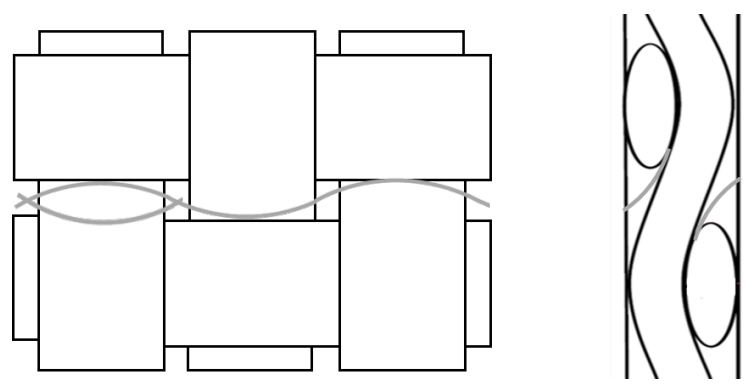

(b)

Figure 6. Schemas of two types of crack modes. (a) Transverse cracks; (b) Wave shape cracks. 

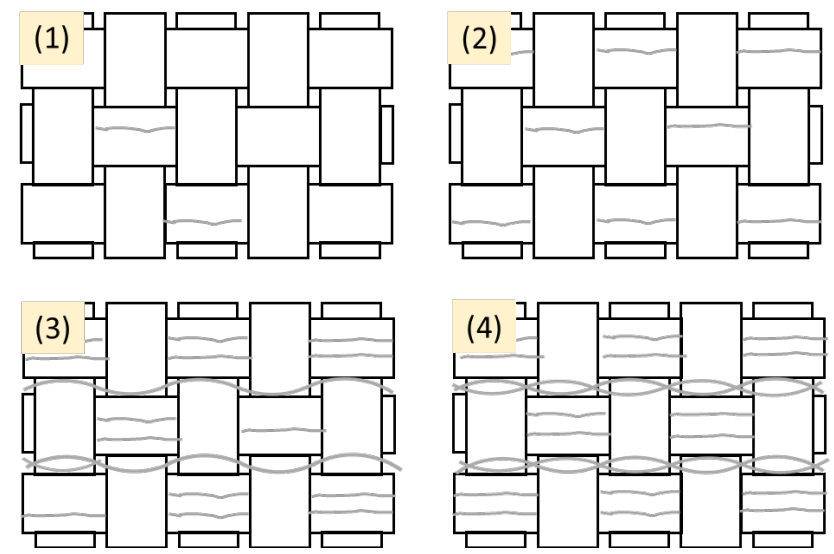

(a)
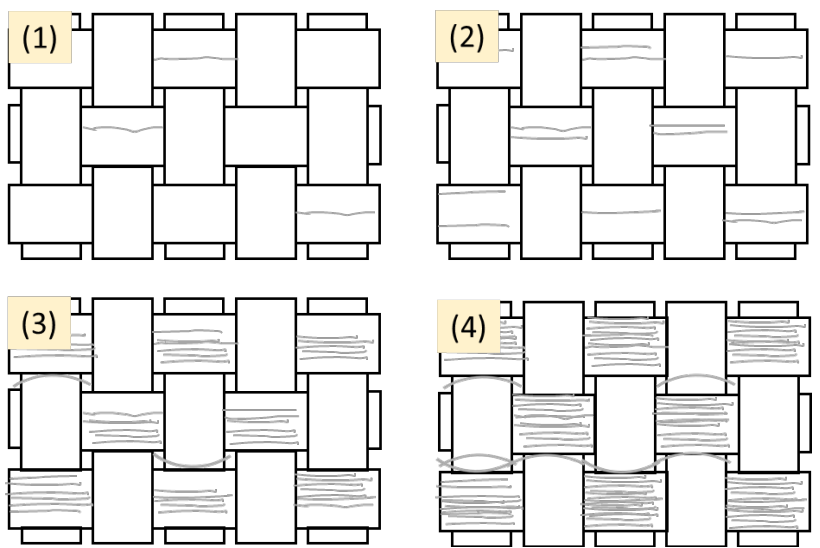

(b)

Figure 7. Schemas of fracture crack propagation. (a) Type A; (b) Type B.

2) During this period, the interface between the glass fibers and the resin is still the main carrier of most of the load. White cracks increased gradually until the cracks went through the transverse fiber bundles. It can be seen that transverse cracks within Type B are much finer than those in Type A.

3) Because of the tendency of the fiber bundle in the crimp to be stretched, the cross section of the warp fiber bundle and weft fiber bundle is compressed and wave shape cracks began to show up both for Type A and Type B. During this period, the interface between the glass fiber and the resin still carried the most of the load but the longitudinal fiber bundles are beginning to take most of the load. More cracks in wave shapes appeared between the transvers fiber bundles were observed in Type A and then increased from Figure 7(a). While for Type $B$, very few wave shape cracks were also observed, and more fine transverse cracks increased.

4) Fourthly, the longitudinal fiber bundles become carrying the most of the load and finally leading to the fracture of the specimen. It was obviously observed that much more wave shape cracks in Type A and propagated in transverse directions. However for Type B, wave shape cracks did not increase much, and plenty of fine transverse cracks were observed within the transverse fiber bundles. 
When comparing Type A with Type B, the difference was observed from the second period. In the case of Type $B$, more and finer cracks were observed, while for Type A, more wave shape cracks propagated during the third and fourth period. AE results showed in Figure 8. It can been seen that the accumulated AE conus of Type A increased faster than that of Type B and kept higher above Type B. Comparing observation results with $\mathrm{AE}$ results, it can be considered that the wave shape cracks resulted in the main fracture and finally leading to the fiber bundle breaking along the load direction. Even the crimp ratio of Type A is higher than that of Type B, the wave shape cracks led to fiber bundle breaking and specimen of Type A came to final fracture before it achieved a high elongation. On the contrast, the higher fiber bundle tex and lower crimp ratio of Type $B$ makes it more tolerant with transverse cracks, and it is considered the specimen was stretched smoothly finally with a higher elongation than Type A.

Higher crimp ratio might lead a tendency to fierce wave shape cracks and result in a low tensile strength. But it is also predictable that the fabric reinforcement with a very low crimp ratio will also not achieve good tensile properties because of the low fiber volume fraction. It is considered that for woven fabric reinforced composites, there is a critical crimp ratio which contributes to better tensile properties.

\subsection{Tensile Results of Off-Axis Cases}

Tensile test was also carried out on specimens of $5^{\circ} / 10^{\circ} / 80^{\circ} / 85^{\circ}$ and the tensile results were summarized in Table 3.

The summary of tensile modulus and strength of all 6 degrees of $0^{\circ} / 5^{\circ} / 10^{\circ} / 80^{\circ} / 85^{\circ} / 90^{\circ}$ are illustrated in Figure 9 and Figure 10 separately. Comparing to Figure 7 and Figure 8, difference between on-axis and off axis can be seen obviously, that specimens of off-axis have much lower tensile modulus and strength. Even in the case of 5 degree and 85 degree, tensile modulus and tensile strength decreased dramatically comparing with 0 degree and 90 degree, which can be considered as a result of the shear stress.

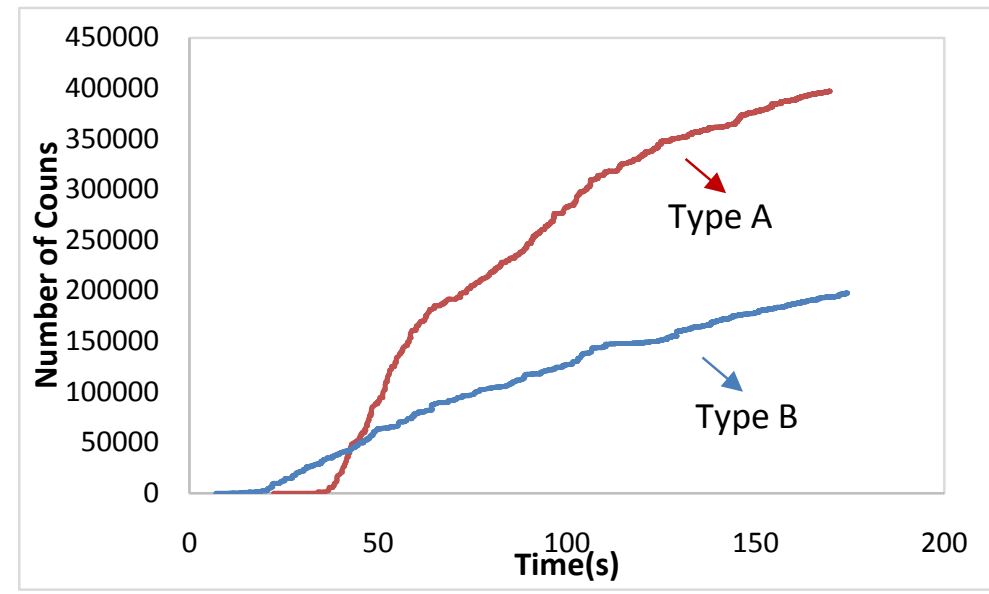

Figure 8. Results of the accumulated AE couns for Type A and Type B. 


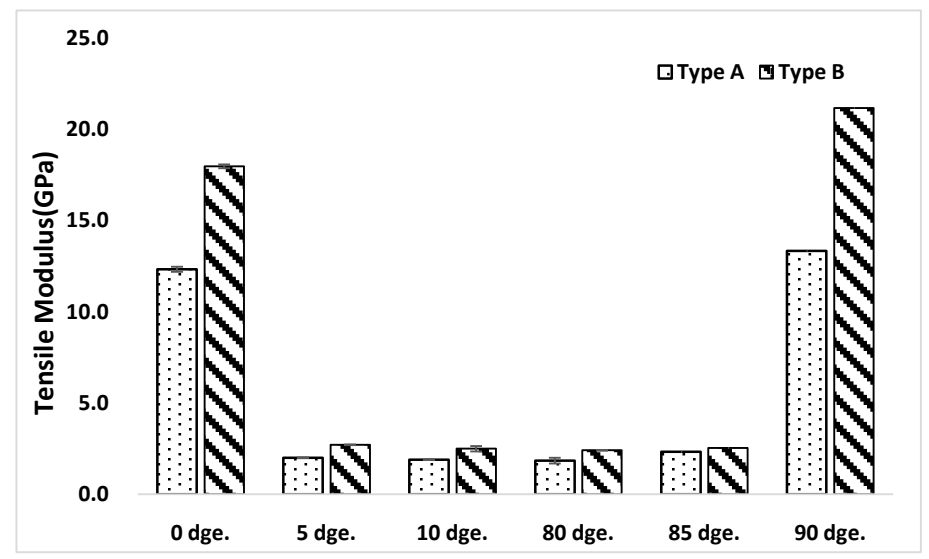

Figure 9. Tensile modulus summary of all 6 degrees.

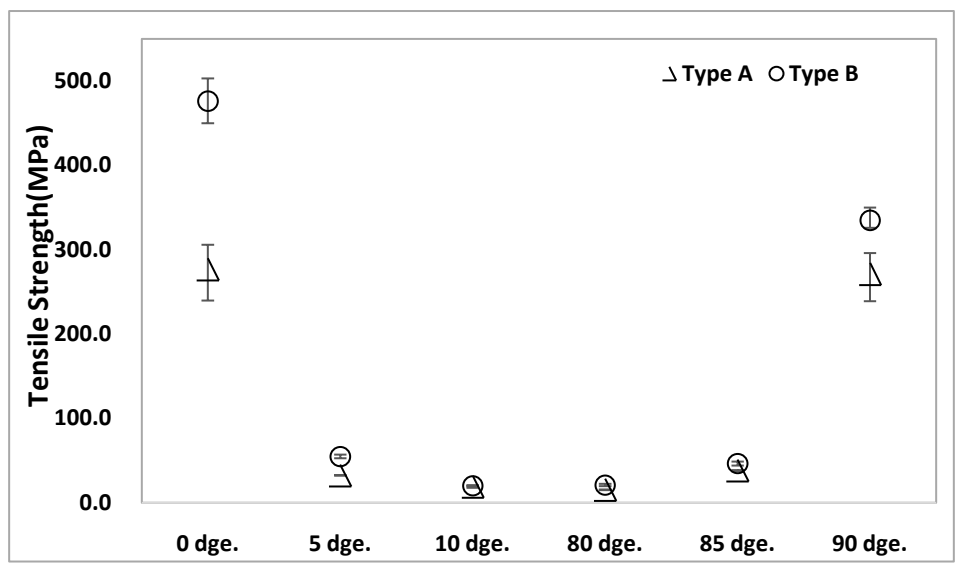

Figure 10. Tensile strength summary of all 6 degrees.

Table 3. Tensile results of off-axis cases for two kinds of GFRP.

\begin{tabular}{ccccccc}
\hline & \multicolumn{2}{c}{ Tensile modulus (GPa) } & \multicolumn{2}{c}{$\begin{array}{c}\text { Tensile strength } \\
(\mathrm{MPa})\end{array}$} & \multicolumn{2}{c}{$\begin{array}{c}\text { Ultimate Fracture Elongation } \\
(\%)\end{array}$} \\
\hline Deg. & A & B & A & B & A & B \\
5 & 2.0 & 2.7 & 32.4 & 54.9 & 3.1 & 2.8 \\
10 & 1.9 & 2.5 & 19.0 & 20.0 & 1.9 & 2.6 \\
80 & 1.9 & 2.4 & 15.4 & 21.0 & 1.5 & 1.7 \\
85 & 2.3 & 2.6 & 38.4 & 46.5 & 2.9 & 3.1 \\
\hline
\end{tabular}

\subsection{Fracture Mechanism Observation}

The photographs of fractured specimens of Type A and Type B after the tensile test were shown in Figure 11 and Figure 12 separately. It can be seen from the photograph that the fracture of 5 degree and 85 degree seemed to be fiercer than that of 10 degree and 80 degree. The fracture schema is illustrated in Figure 13. For 5 degree and 85 degree, cracks propagated along fiber bundles and ultimate fiber fracture happened with the fiber bundle split up. It seems no big difference between Type A and Type B. While it also can be observed from the schema 


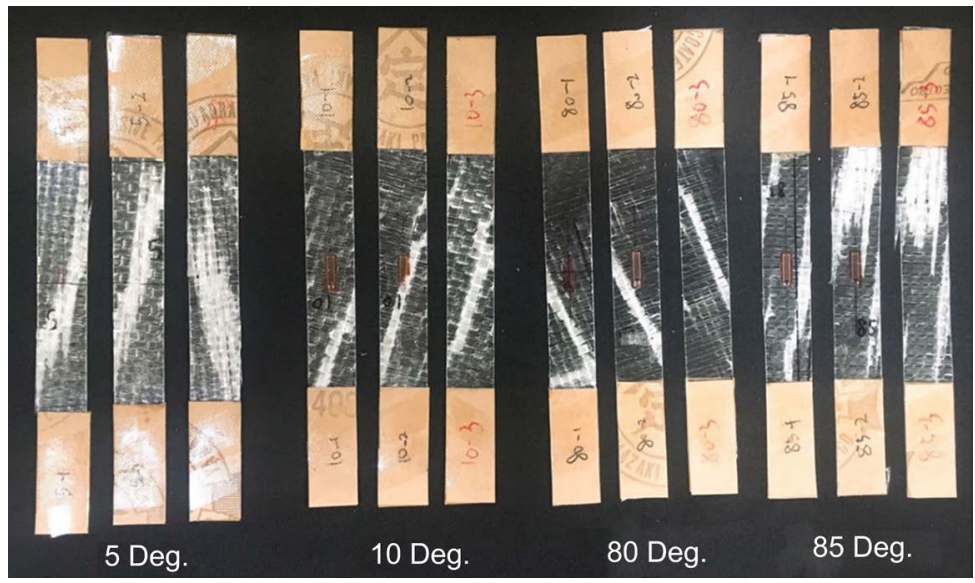

Figure 11. Specimens after fracture for off-axis case of Type A.

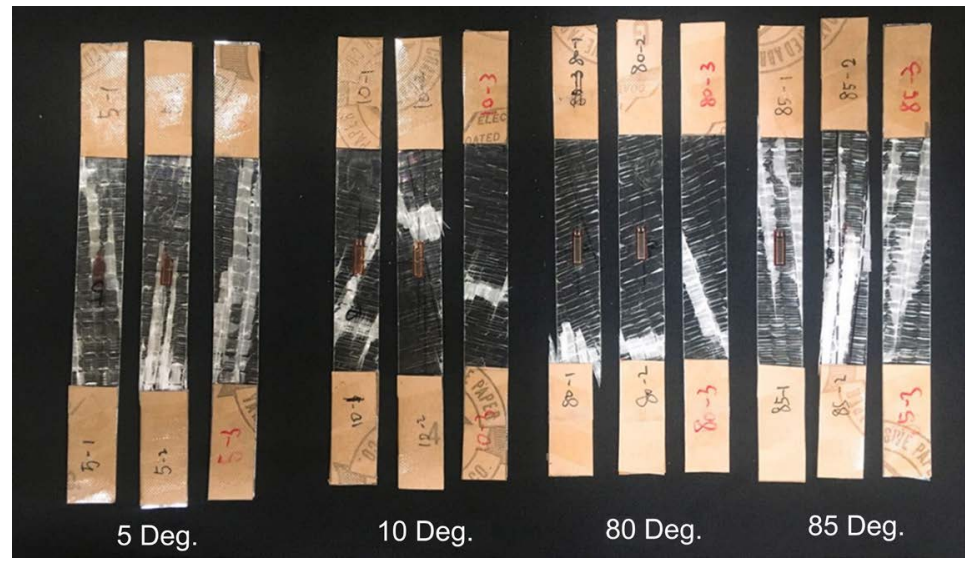

Figure 12. Specimens after fracture for off-axis case of Type B.

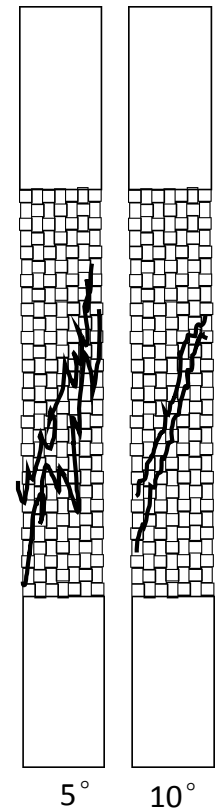

(a)

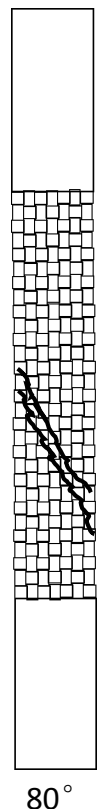

)

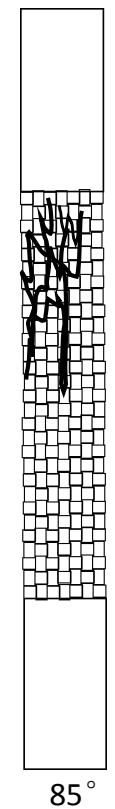

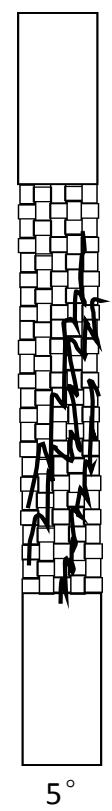

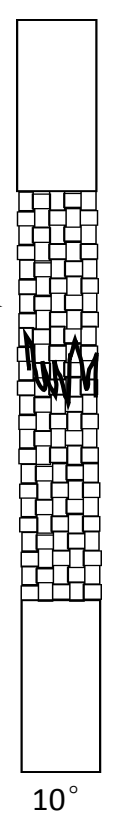

(b)

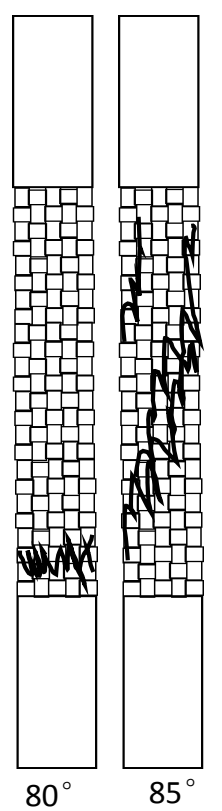

(b)

Figure 13. Ultimate fracture schema of off-axis cases. (a) Type A; (b) Type B. 
that, in the case of 10 degree and 80 degree, especially for Type B, it can be observed that less fiber was pulled out and split, which revealed that the fiber bundle in the loading direction did not take most of the loading. And the shear stress played an important role during the tensile test, leading to the ultimate fracture of the specimen, which can be considered as the reason of the low strength in the case of the 10degree and 80 degree. Especially for Type B, there are very few fiber bundles pulled out and split in the case of the 10degree and 80 degree, and contacted with the tensile strength result which showing a decrease of more than $45 \%$ comparing with 5 degree and 85 degree.

\section{Conclusion}

In this paper, tensile properties, especially the initial fracture properties of two types of roving glass cloth reinforced composites were tested. Tensile test was conducted and tensile properties were discussed on 6 degrees $0^{\circ} / 5^{\circ} / 10^{\circ} / 80^{\circ} / 85^{\circ} / 90^{\circ}$. The tensile results of 0 degree and 90 degree showed that the Type B has higher tensile modulus and strength than Type A. As it is referred to the initial fracture behavior 4 stages have been observed, according to the main load carrier changed from the interface of glass fiber and the resin to the longitudinal fiber bundles. More cracks in wave shape were observed as the crack propagating, while more fine cracks in the transverse fiber bundles were observed in the case of Type B. The important role of crimp ratio was made clear, which can be considered of significance to obtain better tensile property. Among the cases of $5 \% 10^{\circ} / 80^{\circ} / 85^{\circ}$, dramatic decrease in tensile modulus and strength was made clear. And it seem that less fiber bundles pulled out from the specimen during the fracture in the cases of $10^{\circ}$ and $80^{\circ}$, revealing that less longitudinal fiber bundles carried the load.

\section{References}

[1] Xu, F., Fan, W., Zhang, Y., Jia, Z., Qiu, Y. and Hui, D. (2016) Modification of Tensile, Wear and Interfacial Properties of Kevlar Fibers under Cryogenic Treatment. Composites Part B: Engineering, 116, 398-405.

[2] Xie, J., Yao, L., Xu, F., Li, Y., Shan, Z., Hui, D., et al. (2014) Fabrication and Characterization of Three-Dimensional PMR Polyimide Composites Reinforced with Woven Basalt Fabric. Composites Part B Engineering, 66, 268-275. https://doi.org/10.1016/j.compositesb.2014.05.028

[3] Akmar, A.I., Lahmer, T., Bordas, S.P.A., Beex, L.A.A. and Rabczuk, T. (2014) Uncertainty Quantification of Dry Woven Fabrics: A Sensitivity Analysis on Material Properties. Composite Structures, 116, 1-17. https://doi.org/10.1016/j.compstruct.2014.04.014

[4] Sockalingam, S., Chowdhury, S.C., Gillespie Jr, J.W. and Keefe, M. (2017) Recent Advances in Modeling and Experiments of Kevlar Ballistic Fibrils, Fibers, Yarns and Flexible Woven Textile Fabrics-A Review. Textile Research Journal, 87, 984-1010. https://doi.org/10.1177/0040517516646039

[5] Aliabadi, M.H. (2015) Woven Composites. Imperial College Press, London. https://doi.org/10.1142/p984 
[6] Dell'Isola, F. and Steigmann, D. (2015) A Two-Dimensional Gradient-Elasticity Theory for Woven Fabrics. Journal of Elasticity, 118, 113-125. https://doi.org/10.1007/s10659-014-9478-1

[7] Demircan, O. (2016) Initial and Final Fracture Behaviors of Woven Fabric Composites. Science and Engineering of Composite Materials, 23, 161-177. https://doi.org/10.1515/secm-2014-0178

[8] Laroche, D. and Vu-Khanh, T. (1994) Forming of Woven Fabric Composites. Journal of Composite Materials, 28, 1825-1839. https://doi.org/10.1177/002199839402801805

[9] Mostafa, N.H., Ismarrubie, Z.N., Sapuan, S.M. and Sultan, M.T.H. (2016) Effect of fabric Biaxial Prestress on the Fatigue of Woven E-Glass/Polyester Composites. Materials \& Design, 92, 579-589. https://doi.org/10.1016/j.matdes.2015.12.109

[10] Li, S., Zhu, B., Han, J., Dong, Z. and Qin, X. (2013) Research on Weaving Glass Roving Cloth with GA747 Rapier Loom. Fiber Glass, 3, 006.

[11] Chou, T.-W. and Ko, F.K. (1989) Textile Structural Composites. Elsevier Science Publishers B V, Amsterdam, The Netherlands.

[12] Li, L., Lomov, S.V., Yan, X. and Carvelli, V. (2014) Cluster Analysis of acoustic Emission Signals for 2D and 3D Woven Glass/Epoxy Composites. Composite Structures, 116, 286-299. https://doi.org/10.1016/j.compstruct.2014.05.023

[13] Yu, B., Blanc, R., Soutis, C. and Withers, P.J. (2016) Evolution of Damage during the Fatigue of 3D Woven Glass-Fibre Reinforced Composites Subjected to Tension-Tension Loading Observed by Time-Lapse X-Ray Tomography. Composites Part A: Applied Science and Manufacturing, 82, 279-290. https://doi.org/10.1016/j.compositesa.2015.09.001

[14] Nilakantan, G. and Gillespie, J.W. (2013) Yarn Pull-Out Behavior of Plain Woven Kevlar Fabrics: Effect of Yarn Sizing, Pullout Rate, and Fabric Pre-Tension. Composite Structures, 101, 215-224. https://doi.org/10.1016/j.compstruct.2013.02.018

[15] Osada, T., Nakai, A. and Hamada, H. (2003) Initial Fracture Behavior of Satin Woven Fabric Composites. Composite Structures, 61, 333-339. https://doi.org/10.1016/S0263-8223(03)00058-8

[16] Penava, Ž., Šimić-Penava, D. and Knezic, Ž. (2014) Determination of the Elastic Constants of Plain Woven Fabrics by a Tensile Test in Various Directions. Fibres \& Textiles in Eastern Europe, 22, 57-63.

[17] García, I.G., Mantič, V., Blázquez, A. and París, F. (2014) Transverse Crack Onset and Growth in Cross-Ply [0/90] s Laminates under Tension. Application of a Coupled Stress and Energy Criterion. International Journal of Solids and Structures, 51, 3844-3856. https://doi.org/10.1016/j.ijsolstr.2014.06.015

[18] Boccardi, S., Meola, C., Carlomagno, G.M., Sorrentino, L., Simeoli, G. and Russo, P. (2016) Effects of Interface Strength Gradation on Impact Damage Mechanisms in Polypropylene/Woven Glass Fabric Composites. Composites Part B: Engineering, 90, 179-187. https://doi.org/10.1016/j.compositesb.2015.12.004

[19] Almuhammadi, K., Alfano, M., Yang, Y. and Lubineau, G. (2014) Analysis of Interlaminar Fracture Toughness and Damage Mechanisms in Composite Laminates Reinforced with Sprayed Multi-Walled Carbon Nanotubes. Materials \& Design, 53, 921-927. https://doi.org/10.1016/j.matdes.2013.07.081

[20] Ono, K., Fujii, Y. and Wada, A. (2015) Investigation of Non-Destructive Examination for Mechanical Damage of FRP. In: ASME 2015 International Mechanical Engineering Congress and Exposition, American Society of Mechanical Engineers, New 
York, V009T12A029. https://doi.org/10.1115/IMECE2015-52706

[21] Broutman, L. (1969) Measurement of the Fiber-Polymer Matrix Interfacial Strength. Interfaces in Composites. ASTM International, West Conshohocken.

[22] Dixit, A. and Mali, H.S. (2013) Modeling Techniques for Predicting the Mechanical Properties of Woven-Fabric Textile Composites: A Review. Mechanics of Composite Materials, 49, 1-20. https://doi.org/10.1007/s11029-013-9316-8

[23] Zako, M., Uetsuji, Y. and Kurashiki, T. (2003) Finite Element Analysis of Damaged Woven Fabric Composite Materials. Composites Science and Technology, 63, 507-516. https://doi.org/10.1016/S0266-3538(02)00211-7

[24] Xu, Z., Ichikawa, D. and Yang, Y. (2015) Initial Fracture Behavior of Intra CF/GF Woven Fabric Composites. In: ASME 2015 International Mechanical Engineering Congress and Exposition, American Society of Mechanical Engineers, New York, NV02BT02A013.

[25] Xu, Z., Nakai, A., Yang, Y. and Hiroyuki, H. (2017) A Study on the Initial Fracture Behavior of CF/GF Intra-Hybrid Woven Fabric Reinforced Composites. Open Journal of Composite Materials, 8, 11. https://doi.org/10.4236/ojcm.2018.81002

[26] Bussiba, A., Kupiec, M., Ifergane, S., Piat, R. and Böhlke, T. (2008) Damage Evolution and Fracture Events Sequence in Various Composites by Acoustic Emission Technique. Composites Science and Technology, 68, 1144-1155.

[27] Morii, T. and Okamoto, T. (2017) Effect of Fiber Architecture on Acoustic Emission Characteristics of Glass/Polyester Composites. Design, Manufacturing and Applications of Composites.

[28] HaghiKashani, M., Hosseini, A., Sassani, F., Ko, F.K. and Milani, A.S. (2017) The Role of Intra-Yarn Shear in Integrated Multi-Scale Deformation Analyses of Woven Fabrics: A Critical Review. Critical Reviews in Solid State and Materials Sciences, 43, 1-20. 